\title{
Approaches to Spatial Analysis in a Local Cinema History Research
}

\begin{abstract}
In a growing interest in spatial visualisation of historical data emphasized within the field of the new cinema history, identifying the methodologies, their benefits as well as obstacles, is crucial for the development of optimal approaches to the research of the past of the local film culture. The main goal of this paper is to introduce several possibilities of treatment of historical data in a geospatial context. On the case study on the local cinema history and culture in Brno, the Czech Republic, during the I930s, this paper proposes methodologies of visualisation and analysis of historical data transferred to the spatial context, identifies the challenges of visualisation of ambiguous qualitative data and introduces the treatment of temporal dimension of data within geographical space. This paper aspires to become a contribution to growing field of spatial approaches to cinema history. It proposes several methodologies of how to visualize, analyse and understand historical data in spatial-temporal context.
\end{abstract}

KEYwORDS: Spatial analysis; comparative research; local film history; Brno; I930s; programming analysis

'GIS is a seductive technology, a magic box capable of wondrous feats, and the images it constructs so effortlessly appeal to us in ways more subtle and more powerful than words can.'I

Geospatial visualisation is a methodology enabling us to display, explore and analyse historical data in its spatial and temporal dimension and to seek new relations between spatial as well as non-spatial objects and variables. Cinema history and film culture studies examine the possibilities of applying this methodology to specific historical data and exploring the contribution to the research within the field of study. This paper explores the possibilities of spatial visualisation and analysis of historical data, bringing forward its advances as well as challenges, on a case study on the history of cinemas and film culture in Brno, Czech Republic in the I930s. It presents ways of combining data of diverse nature into one map and helps to understand the spatial as well as temporal relations between the elements that may have otherwise remained unnoticed. It seeks new angles of looking at historical materials by designing optimal combinations of variables into a complex geospatial visualisation. 


\section{Theoretical background}

In recent years, many cinema history research projects have adopted an approach that rewrites cinema history 'from below'2 by focusing not on the strategies of production and distribution companies, but rather on the local practices of cinemas, film exhibition and consumption. ${ }^{3}$ The use of geospatial analysis and visualisation of local historical cinema cultures, however, has rarely become a main research practice. Several academic projects on cinema history have resulted in extensive map databases, such as, for example, Robert C. Allen's Going to the Show, Jeffrey Klenotic's Mapping Movies, or the Australian Cinemas Map led by Richard Maltby, ${ }^{4}$ using maps to localise cinemas within a geographical space (Going to the Show, Australian Cinemas Map) and introducing additional spatial or non-spatial entities (for example, the gender distribution by state in the Mapping Movies project).

The methodology of geospatial visualisation is an ongoing process of decision-making regarding which data to incorporate and which to omit in order to achieve the optimal balance of clarity and complexity of the final result. In the following cinema history projects, the visual representation of data tends to apply a rather graphical display, losing part of the geographical information for the purpose of maintaining the clarity of the final result.

Sébastien Caquard, Daniel Naud and Benjamin Wright, in their research on mapping film audiences in Canada, developed the graphomap, a 'hybrid form of visualization between a graph and a map.'5 By reducing the two-dimensional map representation (latitude and longitude) to one dimension (the longitude) they allow visualisation of two variables - in this case, the revenues of a given film in each theatre and the sociodemographic profile of the area where the cinema is located - simultaneously in one display. According to the authors, the loss of one spatial dimension does not have a major impact on the results, as most of the cinema venues are located in the southern part of the country. This model has its limits in representing more spatially diffused objects as well as displaying greater variety of sociodemographic categories (the given example visualises cinemas according to the percentage of immigrants living near them, but without closer specification of their origin), which makes it hardly transferable to historical researches of different localities, unless they possess similar spatial characteristics.

In a case study on the history of cinema venues in Melbourne, Alwyn Davidson builds a similar, but more graphical, visualisation of spatial and temporal historical data and additional characteristics of places, seeking to 'extend the spatial presence in information graphics' and to create a 'holistic treatment of time'. 6 Her petal diagrams reduce the geographic location of cinema venues to 'classes of direction and distance' from Melbourne city centre, thanks to which she achieved more specific visualisation of the temporal aspect of the data. This method also enables visualisation of multiple variables of cinema venues, such as their names, any changes of their size throughout a given period and the role of the cinema company. In an effort to visualise the temporal element in detail, the spatial element becomes one of the categorisation applied to the data but tells us nothing about the actual spatial positioning of the venues. This methodology perfectly serves its purpose to visualise a change in time, but it reduces the spatial aspect to a minimum. 
Even more space reducing are the 'olive trees', a methodology that visualises the trajectories of films moving between the cinemas of the Greek diaspora in Australia, as developed by Deb Verhoeven and Colin Arrowsmith.7 To focus specifically on the temporal dimension of the analysis, the spatial characterisation of cinemas is visualised in an abstract form represented by the colour of the leaves and olives on the trees. In contrast, their next case study on mapping metropolitan Melbourne cinema during I954-I970 shows the opposite approach. While keeping the geographical localisation of cinemas visualised on a map background outlining the area of Melbourne city, the main category of space here is the distance of cinema venues from the city centre. The representation of the change in time was divided to several map images, each representing either the openings or closings of the Melbourne cinema venues during one of the four periods. The result consists of eight maps aiming at mutual comparison.

The methodology introduced in this paper applies an approach trying to maintain the spatial dimension in its richness while engaging the temporal element only partially. Stressing the spatial element enables the researcher to carry out spatial analysis of visualised objects in the context of their geographical environment enhanced by several thematic map layers bearing visualisations of diverse characteristics of the place, using historical data of the case study on the history of cinema venues and their film exhibition strategies in Brno, Czech Republic, during the ig3os.

\section{Data set and methodology}

The data set used for this case study consists of a wide collection of programming data, data on cinemas in Brno and oral history covering the period from the beginnings of cinema exhibition in Brno to the end of World War II. This data set was created during the research project 'Cinematic Brno' at Masaryk University in Brno, which resulted in a rich digital database on the history of cinemagoing in Brno. ${ }^{8}$ The spatial visualisation engages the results of quantitative analysis of programming data (for instance, the popularity of national productions in cinemas or a proposed cinema ranking system) and qualitative characteristics of spatial elements (such as the social structure of city districts or the history of the construction of the tramway network).

This paper aims to accentuate the spatial element of map visualisation, its meaning and possible application in the analysis of historical data. It exploits the ability of a geographic information system (GIS) to combine spatial information with non-spatial data, allowing new comprehension of a historical event. GIS operates as a set of map layers, each representing a specific theme and linking to a concrete location within the geographical space. Layering the maps on each other, thematic maps can be created. Thematic maps offer the possibility to localise objects within the space and visualise their characteristics. 9 They provide an opportunity to compare geographic locations of cinema venues based on their quantitative and qualitative characteristics, while helping to understand the choices of cinema owners to establish their business in a given area. However, as Jeffrey Klenotic states, it should not be forgotten that 'thematic maps must necessarily be taken as partial and limited representations of space', 
because space and time are strongly connected and continuously developing space could not be perceived in its entirety when frozen in time. ${ }^{\text {I0 }}$ Another limitation of map visualisation is its lack of capability to represent ambiguities, nuances or uniqueness of evidence, which are typical to research materials in humanities. ${ }^{\text {II }}$ This paper seeks to challenge the visualisation of ambiguities and representation of time processes while keeping the geospatial dimension at its full extension.

This contribution builds upon the findings of a broader research of Brno film culture and cinema history in the I930s: the results of the analysis of daily cinema programmes, the popularity of national film productions across the city, the proposed structure of cinema rankings and the screening history of selected films. It strengthens the role of geographical space in the analysis of historical data, sheds light on their spatial relationships and raises new research questions.

\section{Cinema allocation, distance and density}

Space plays an important role in cinema history research. The allocation of cinema venues within the city (Map I) first reveals a differentiation of the visualised space: the east of the city possessing a high number of cinema venues, versus the almost empty areas in the west and south. Only after adding more spatial features to the map does the pattern of cinema allocation become more specific. On Map 2, the layer with cinemas overlaps the background historical map and the layer with tramway lines. The cinema positions can be interpreted thanks to the proximity analysis based upon the calculation of distances, defining the relationship of the venues to the neighbouring tram lines and the city centre. The highest density of cinema venues can be found in the central area within one kilometre of Freedom Square. Cinemas lying at a greater distance are spread around the city in several clusters, while others stand alone. The position of clusters indicates that cinemagoing was far more popular in the eastern and northern districts of Brno than in the southern and western parts, where only a handful of cinema venues operated. The relation to the tramway network seems similarly significant, with the majority of cinema venues lying within 300 metres of the tramline. Even though the localisation of tram stations was not reconstructed, Map 3 confirms the presumption that proximity to the tramway did play a role in the decision-making of cinema owners regarding where to locate a new venue. On this map, the tram lines and cinemas were categorised by colour according to the year of construction. Generally, new venues were opened only after the tramway had been extended into a particular neighbourhood, and thus the tramway could be perceived as a way of bringing cinema culture to the more distant areas of the city.

There are few exceptions, such as, for example, the cinemas Bio Slávia and Bio Hvězda, which were built six years before the tramline was laid nearby. Both cinemas were founded in I922, with neither serving exclusively for film screenings. They were neighbourhood cinemas, also operating as community centres, dance halls, theatres and sport centres. ${ }^{\mathrm{I2}}$ Until I9I9, the district of Židenice, where both cinemas were located, existed as an autonomous municipality. The cinemas thus maintained an important role in the social life of inhabitants of this area, which later became recognised as one of Brno's districts. 


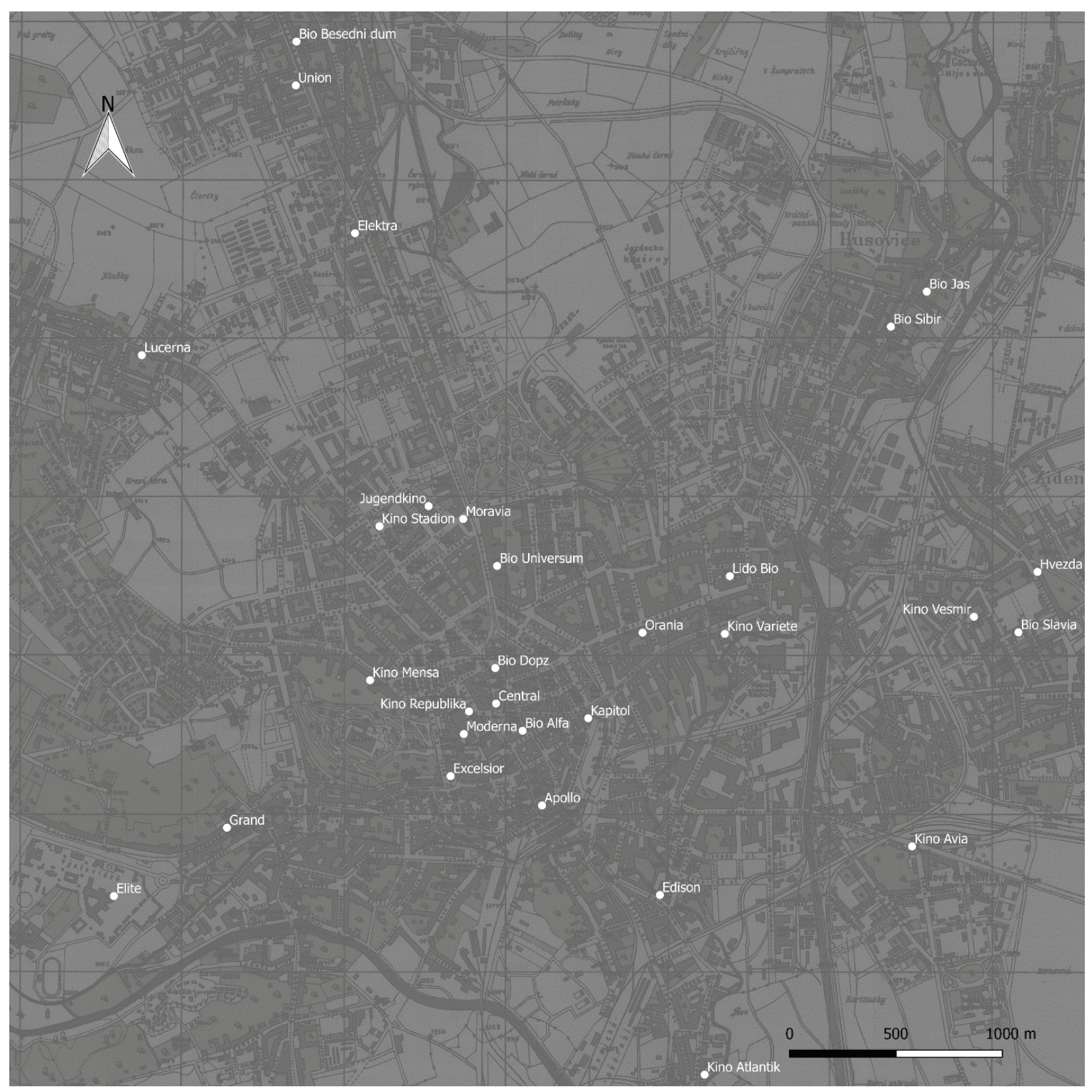

Map 1. Location of cinemas in Brno in the 1930s. All maps are produced by the author.

The reasons for locating a cinema near the public transport system include the constant need to transport heavy cans of film prints between the cinema and the train station. This presumption, however, can be challenged by the danger the cans posed to the other passengers, considering that the film stock was highly flammable. Another reason is improved access to the venue for cinemagoers from a broader area of the city. However, in this interpretation we need to consider the prices of tram tickets in the I930s, which were often as high as a cinema ticket and could not be afforded by the lower social classes, who may have preferred to walk and save the money for more auspicious occasions. ${ }^{13}$

The proximity analysis brings a new angle to looking at the cinema position within the geographical space. It raises a new set of questions regarding the relationship between the cinemas and the means of transport, as well as the background and the status of the venue within its environment. It clusters cinemas according to the rule of distances, which can be further researched, such as, for example, if there is any particular reason why there is almost no cinema located between the second and third kilometre from the city centre. 


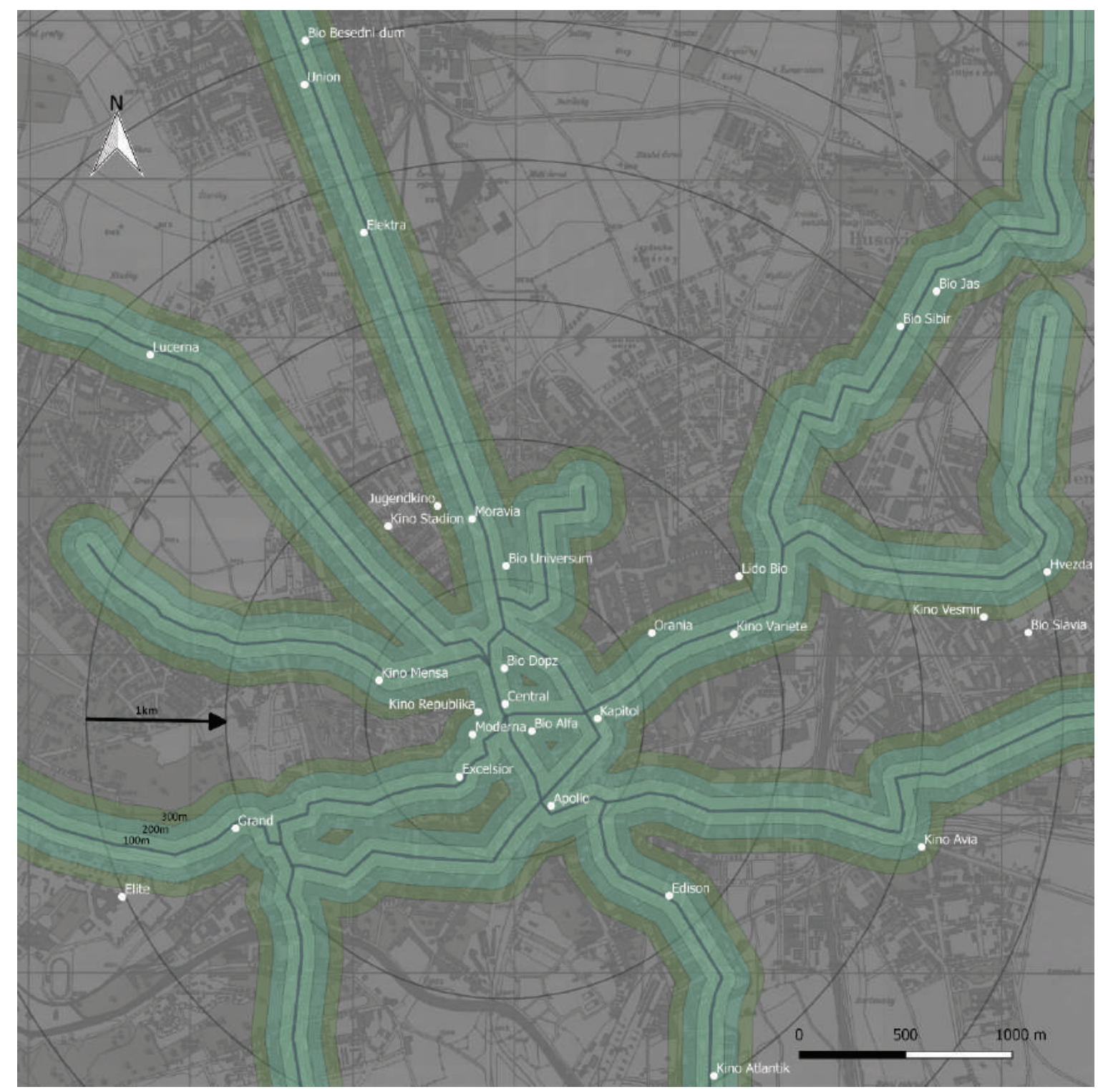

Map 2. Proximity analysis: buffers of $100 \mathrm{~m}, 200 \mathrm{~m}$, and $300 \mathrm{~m}$ distances from the tramways.

\section{The change in time}

Spatial visualisation can also work, to a certain extent, with the temporal dimension - for instance, in displaying the changes of the sizes of cinema venues at the beginning and end of the I930s. Map 4 consists of two point layers representing the size of cinemas based on the number of seats. This case study operates with the entire period of the I930s, and during these ten years, many cinemas changed size several times. The visual representation of these changes, however, is limited to show only their size in I930 and their final size in I939. This decision was made to maintain readability of the map and to capture the main trends of these changes over time. Even though the resulting map shows three different colours, both point layers have only a single colour. The background historical map is superimposed with a layer that has blue circles representing the sizes of cinemas in I930. The second layer, with pink, semi-transparent circles, lies on top of it and represents the sizes of cinemas in 1939. Thanks to the semi-transparent colour, an additional purple colour appears, showing the conjunction of these two layers. 


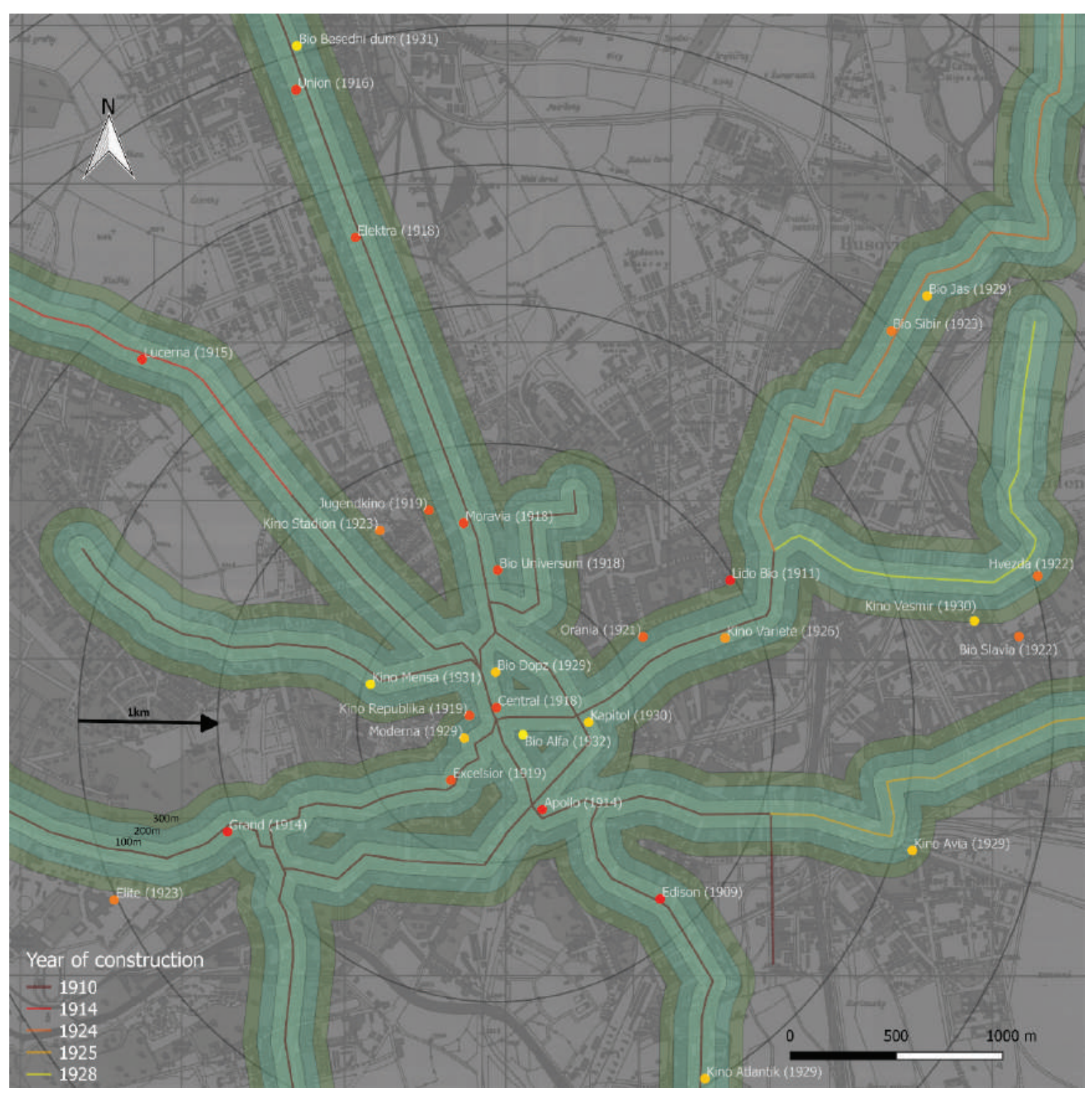

Map 3. Tramway network and cinemas categorized according to the year of construction.

The changes of size are clearly visible: cinemas such as Bio Dopz or Bio Slavia, with a pink circle oversizing the purple one, had grown bigger by the end of the period. A single purple colour represents the absolute overlap of blue and pink, meaning that a cinema had the same number of seats at the beginning as at the end of the period. If the colour of a circle is only pink (for example Bio Alfa) or only blue (for example Apollo), the cinema either was not in operation in I930, or it finished its service before I939, respectively. The overall pattern on this map, with the majority of cinemas maintaining or even increasing their size, suggests a blooming popularity of cinema culture during the I930s in Brno.

This type of visualisation, showing a change in time, points out a general phenomenon of the growing popularity of film culture. However, it supresses the nuances that may have happened during the decade. The geospatial dimension in this case brings forward the relationship between the size and location of cinema venues, turning a researcher's attention not only to the general pattern of the largest cinemas localised in the city centre, but also to a few exceptions of large cinemas outside of it. 


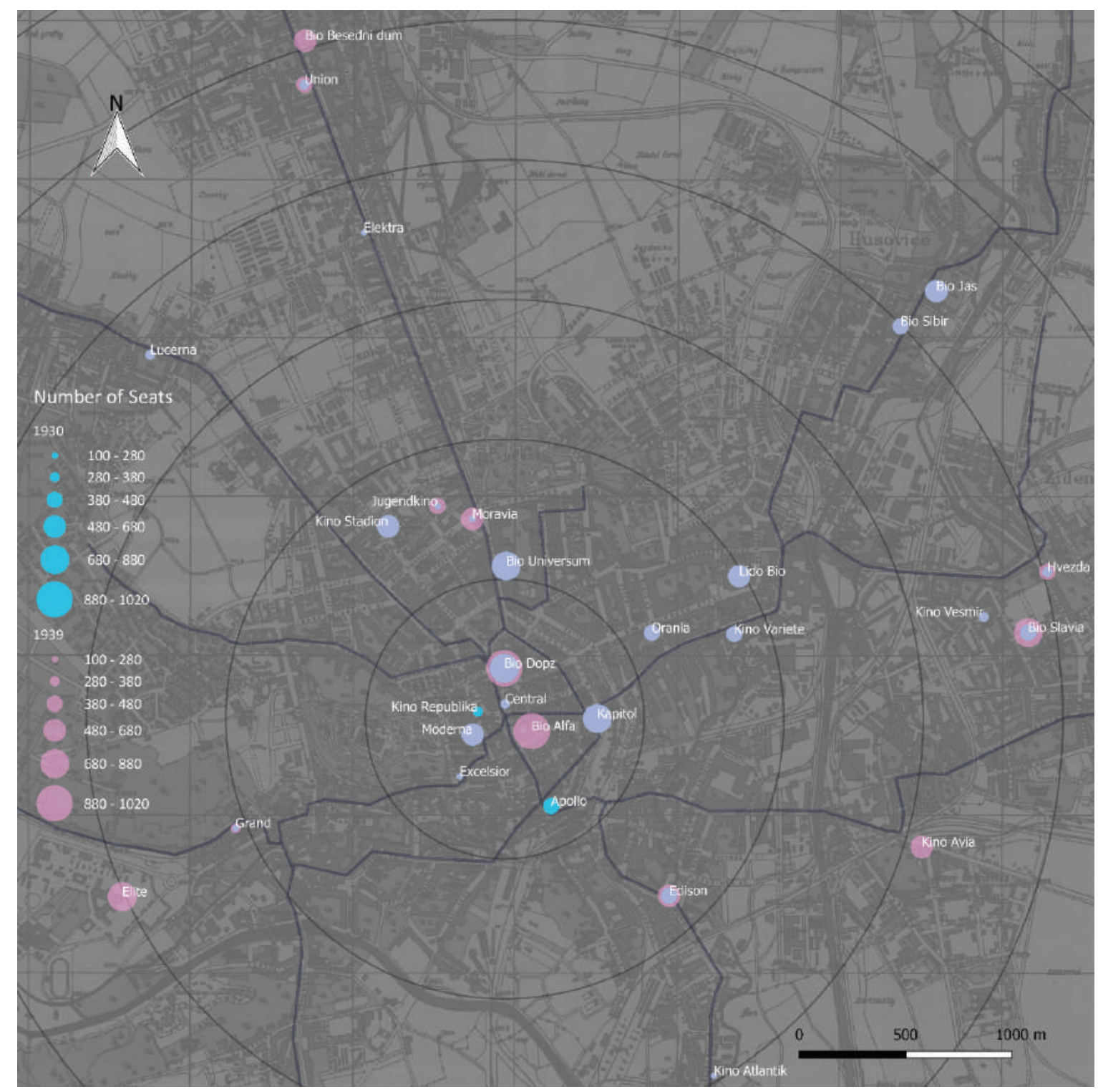

Map 4. Categorisation of cinemas according to their sizes in 1930 and in 1939.

\section{Ranking, distance and social structure}

A slightly different pattern stands out if the cinemas are categorised by proposed rankings as opposed to size (Map 5). The analysis of the ranking system consisted of a categorisation of cinemas according to their most frequent position in the succession of venues through which the exhibition trajectories of films led. The first-run (or premiere), second-run and third-run cinemas were distinguished, while identification of lower rankings had become more complicated, as the frequencies spread evenly among several positions and the sources for programming data were missing or incomplete.

The pattern of cinema locations in relation to their ranking presents a very traditional model with all the premiere cinemas in the central area, while the lower ranks appear mainly in the city districts. Concerning the second- and third-run cinemas spreading around the districts, the pattern signifies that both were present in almost every neighbourhood. They supplied the community with relatively fresh programmes for lower prices than the central first-run cinemas. 


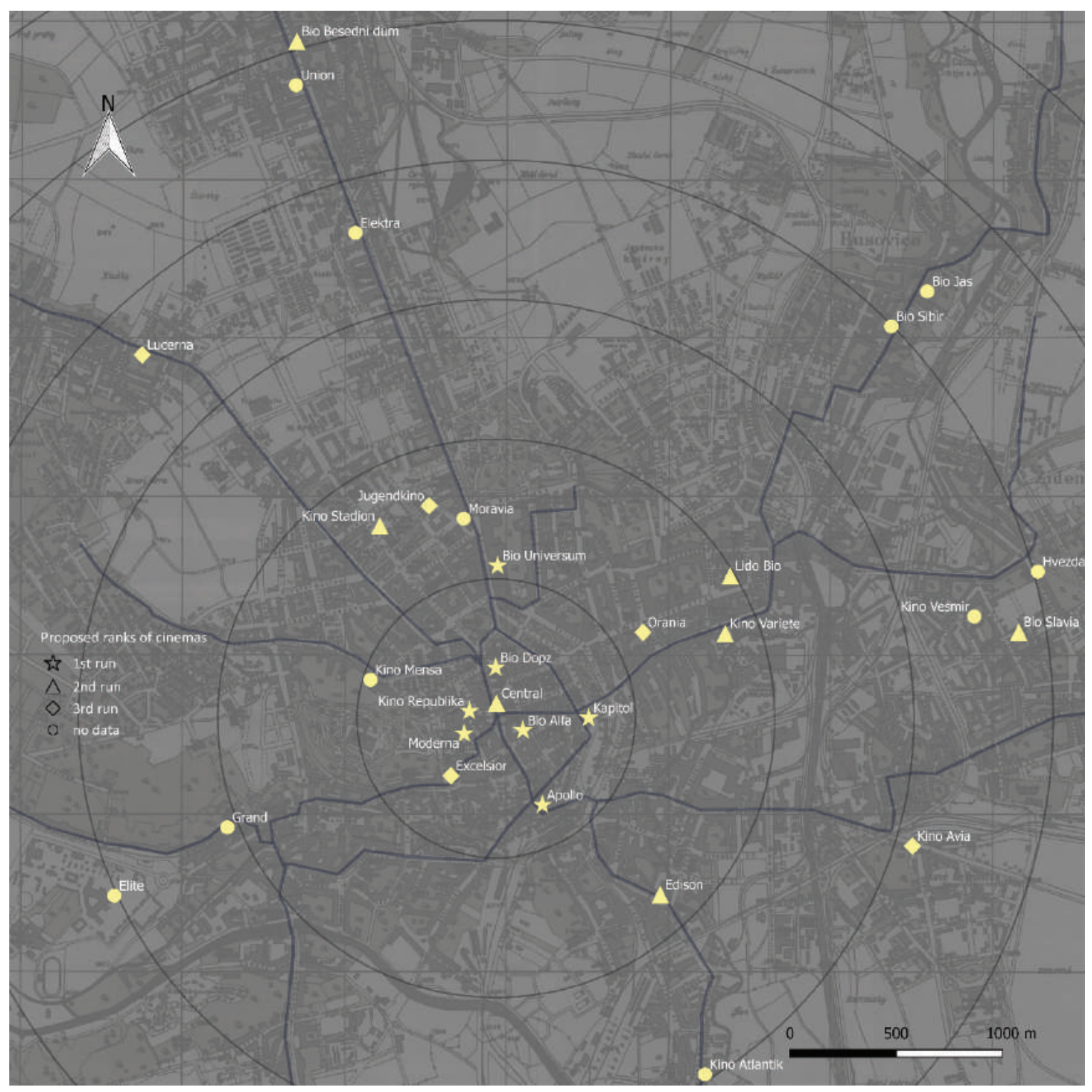

Map 5. Categorisation of cinemas according to the proposed ranking system.

However, if additional characteristics of space are added to the map, such as the social structure of the city, the pattern again becomes far more specific. The position of cinema venues was certainly not formed by a single factor alone. As mentioned before, the cinema network extends more to the eastern parts of the city, leaving the west of the city relatively empty. One of the reasons for such an uneven distribution can be revealed in the context of the city's social structure. Map 6 divides the city into several parts according to the prevailing social status of their inhabitants. This social structure reflects the architecture of the city and social characterization of the city districts, described in the Brno Architecture Manual, ${ }^{14}$ as well as memories of interviewees intuitively linking certain parts of the city with specific social groups. From this point of view, the western parts of the city are mainly covered with high-class residential areas. Together with the districts in the north, they represent the broadest areas with almost no cinema venues. Only the cinema Lucerna, to the north-west of the city centre, is located most definitely within a high-class residential area, while the cinemas Grand and Bio Universum bordered on areas with different social profiles. The higher density of cinema venues in the middle-class and lower-class neighbourhoods indicates that cinemagoing as a leisure activity had a considerable place in the lives of their inhabitants. 


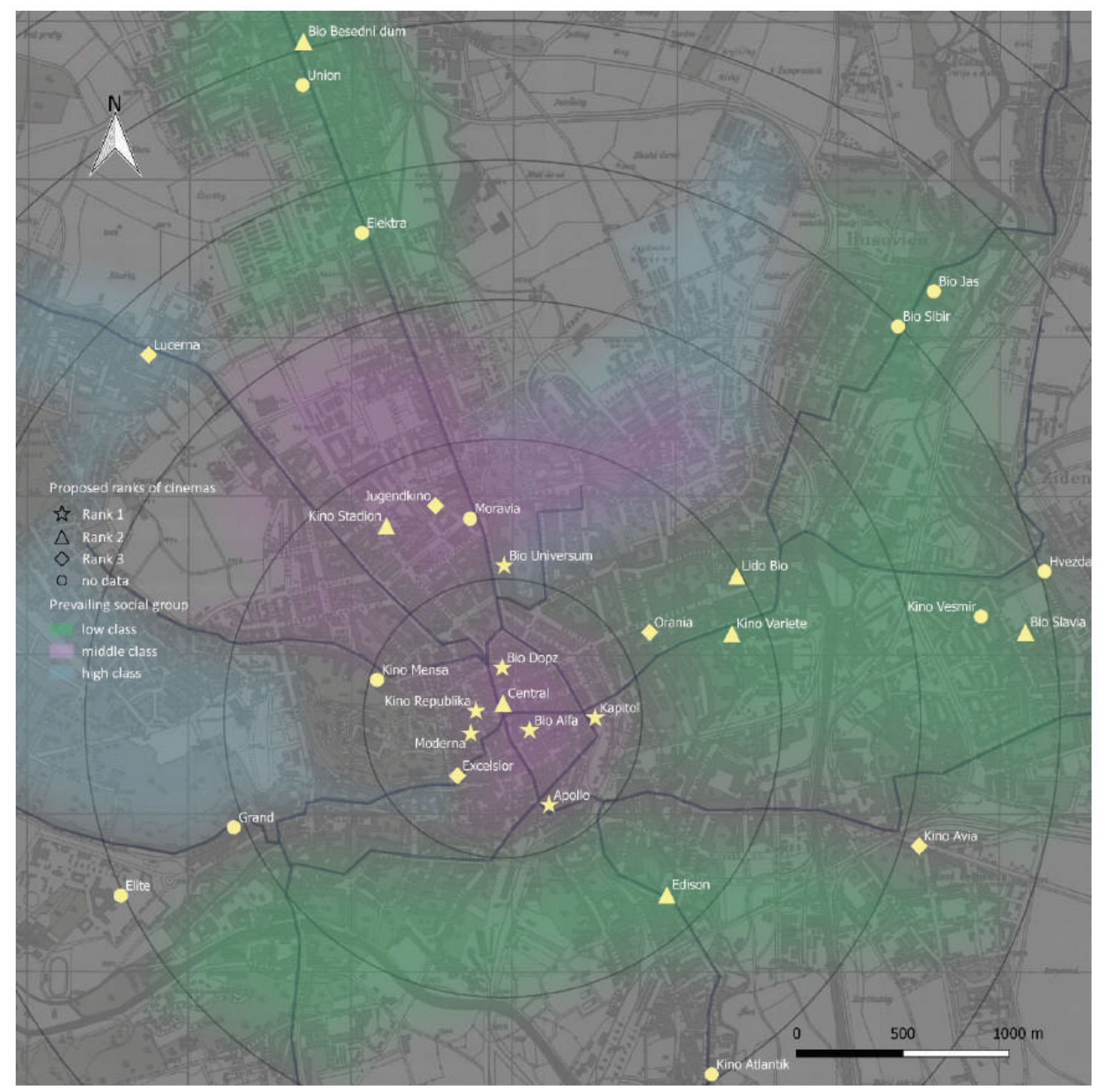

Map 6. Cinema ranks and social structure of Brno according to the prevailing social status of inhabitants in the 1930 s.

Previous research on cinemagoing in Brno suggests that cinemas outside the city centre and in the neighbourhoods were not venues exclusively for watching films, but rather places of a wider community life, often providing space for social events such as dances or communal meetings. Visiting the cinema in a neighbourhood was an expression of allegiance to that given area and community, but it was also the most convenient way to watch a film considering the higher prices of cinema tickets in the central area and the greater distance from cinemagoers' homes. ${ }^{15}$ In addition, oral history suggests that the meaning of visiting a cinema in the city centre differed in terms of the social status of the event, its exclusivity and its affordability. Beyond a feeling of fellowship, these events represented the privilege of watching the latest blockbusters in premiere venues that offered greater elegance and comfort. One of the interviewees for the 'Cinematic Brno' project recalled how a visit to a premiere cinema could provide a sense of being part of the high-class lifestyle and presenting oneself in the best possible light. The interviewee mentioned that during the break, the aisles of the auditorium became a sort of catwalk where all the ladies posed in their best dresses and new haircuts. ${ }^{16}$ 
Layering the map with cinema dissemination in relation to the social structure of the city sheds light on the relation of various social classes to cinemagoing as a leisure activity. According to the density of cinemas in the lower- and middle-class neighbourhoods, cinemagoing was a common part of the everyday life of its inhabitants, while the absence of any cinemas in highclass neighbourhoods suggests a less communal relation to this leisure activity, with the choice of attending a film screening being seen as part of a broader cultural and social experience offered by entertainment in the city centre.

\section{Popularity and social structure}

These results presuming different types of audiences in different parts of the city have led to a subsequent analysis of the relation between popularity and the national origin of film productions. The goal was, on the one hand, to examine the relation between a cinema's ranking and its preferences for film productions originating from a certain country, and on the other hand, to grasp the changes in preferences during the I930s in relation to the most noticeable changes in the sociopolitical circumstances of the country as well as to the main changes in the film distribution policy.

Analysis of the popularity of national productions is based on the programming structure of each cinema. The POPSTAT formula, developed by John Sedgwick and serving as a tool for analysis of film popularity, could not be used, as the data on cinema ticket prices are missing for the majority of the venues. A markedly simpler estimation of popularity was applied by comparing the number of screening days of films in a given cinema to the average number of screening days calculated separately for each cinema. This formula helped to ascertain the relative popularity of productions from certain countries by establishing the highest number of films of the same country of production from the 900 titles with the highest number of days screened in the city. The limitations of the analysed set of films grew from the time limitations of the initial research on cinemagoing, in which it was not possible to identify the whole database, which consisted of more than 3,400 unique titles screened in Brno's cinemas during the I930s.

During that time, no official censorship regulated the film distribution market and exhibition strategies. There was only one regulation, which concerned cinema ownership. With the aim of preventing the creation of large cinema chains, it restricted individuals to applying for cinema licences prioritising cultural and charity societies and even limiting them to possessing a single cinema licence at any one time. ${ }^{17}$ This leads to the main presumption that the majority of cinemas operated on a business model seeking the highest profit for every screening. According to this presumption, those films screened the longest can be considered the most popular. Films screened the longest were defined as films screened for more than the average number of screening days for a film as defined for each cinema.

To provide the analysis of popularity with valuable results, the decade was divided into four periods (I930-1931, I932-1934, I935-1937 and 1938-1939) according to changes in Czechoslovak film distribution and the broader sociopolitical state of the country. Several changes occurred during the I930s that significantly affected the supply of films to the 
Czechoslovak film market. In I932, the quota system was established which regulated the importation of foreign films. A maximum of imported films was defined, charges on every imported film were entrenched and, moreover, the obligation to produce one film in Czechoslovakia for every seven imported films was introduced. The Motion Picture Producers and Distributors of America, however, did not agree to these conditions determined by the Czechoslovak government and began boycotting the Czechoslovak distribution market. ${ }^{18}$ During the period of the quota system, there was a dramatic decline of American films on the market. After two years, in I934, this austere system was substituted by less strict, registration system. The main goal of this initiative was to entice American production to re-join Czechoslovak distribution, as well as to suppress the proliferation of German influence, which was considered by many Czechoslovaks as a negative one. In I935, the American distribution companies re-entered the Czechoslovak market, updating it with the latest production methods and taking the opportunity to make a profit from the films of the previous three years which had yet to be screened to the Czechoslovak audience. The last period, ending in 1939, is defined by the changing sociopolitical situation and the increasing fear of the aggressive politics of Germany, which had established the Protectorate of Bohemia and Moravia, restricting the import of films and establishing the official rankings of cinemas.

The most visible change that occurred during the decade is the declining popularity of German films and increased popularity of Czech productions. German films had enjoyed a considerable popularity since the beginning of the I930s (Map 7). Even though American-produced films had retained the greatest share of the distribution market during this first period (I930I93I), this was not reflected in their popularity. Petr Szczepanik acknowledges a similar situation in Prague's premiere cinemas as demonstrating the Czechoslovak nation's inclination towards German, and especially Austrian, culture and language thanks to their shared past. ${ }^{\text {I9 }}$ In I932, the Czechoslovak government significantly contributed to this phenomenon by establishing the previously mentioned quota system that instigated the retreat of the majority of the Hollywood distributors from the film market. During the period 1932-1933, only older American films circulated in the market. Without a proper rival, German-produced films flourished during these years (Map 8). However, a change arrived no sooner than I935. With a changing mood of the nation facing the rising power of Hitler and his Nazi party in Germany and the anti-Semitic rhetoric presented in several movies, the quota system was replaced by a less demanding registration system, softening the rules imposed on imports and thus encouraging the Hollywood production companies to return to the Czechoslovak film distribution market and, by their presence, reduce the influence of German film production. From I935 onwards, American-produced films flooded the market again. Despite having the greatest quantity of films on the market, they never reached the popularity of their German counterparts of the beginning of the I930s. American films gained popularity in several cinemas after I935; however, once they regained their place on the market and audiences satisfied their desire for Hollywood blockbusters, the initial sensation subsided, and their popularity declined. Surprisingly, it was Czechoslovak-produced films, with the third highest share on the national distribution market, which became very popular after I935 as a result of the cultural distance of the Czechoslovak audiences from American productions and a newly adopted sociopolitical distance from German productions (Map 9 and Map Io). 


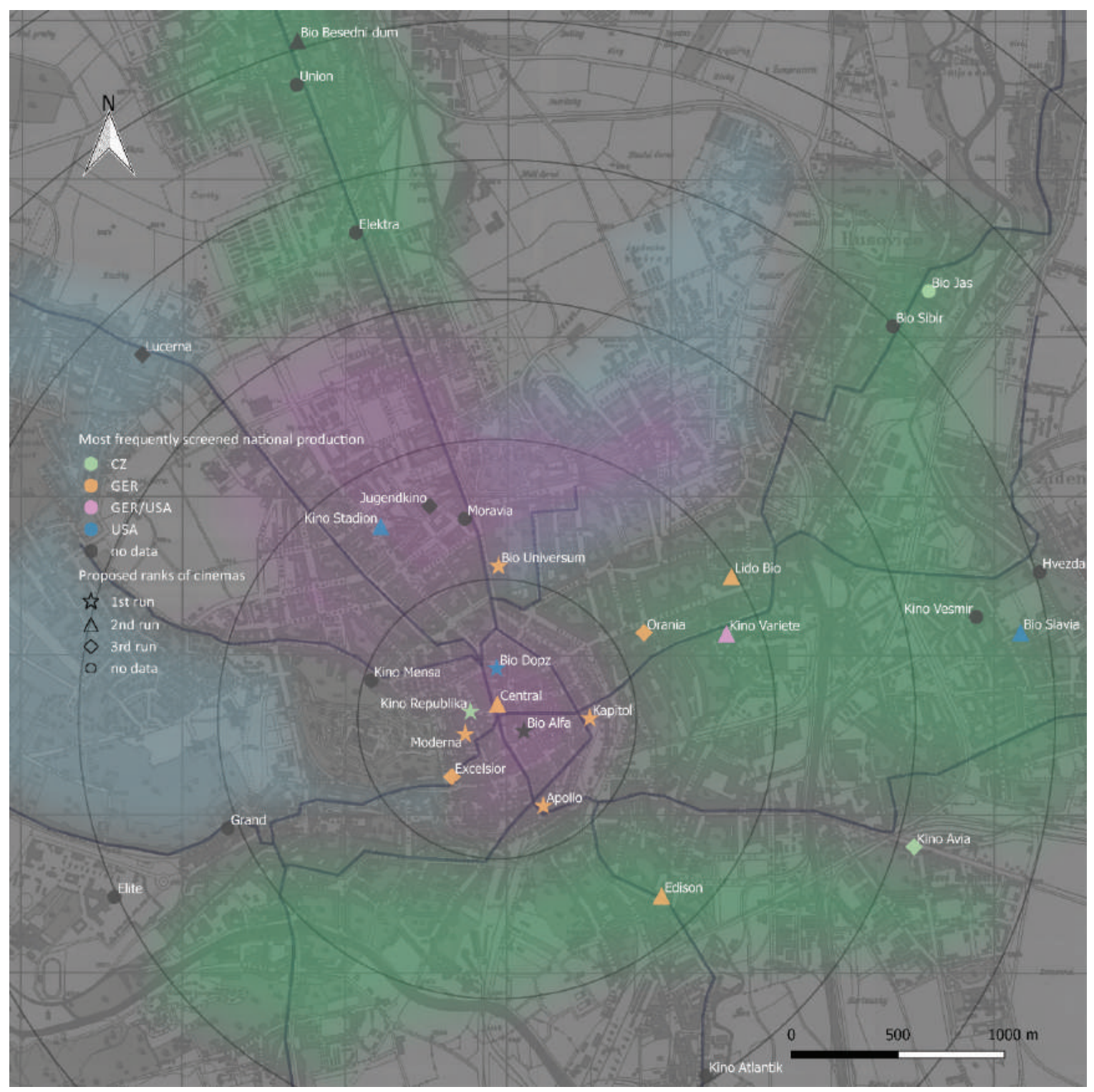

Map 7. Popularity of national productions during the period 1930-1931. Visualisation of the most popular national production in each cinema.

The four maps representing the popularity of various national productions in the four defined periods help us to understand not only the spatial pattern, but also the change in time. The division of the I930s into four periods was prompted by insufficient consistency of the source data set as well as by the hypothesis that the popularity and tastes of audiences were formed by general changes in the distribution policy and sociopolitical circumstances in the country. The restrictions applied to imports, however, had a stronger impact on the structure of the distribution market than on the audiences' preferences. The map of the period I932-I934 shows that even during the American boycott of the Czechoslovak distribution market, older Hollywood films became the most popular in the cinemas Kino Variete and Apollo. On the other hand, enticing American distributors to return to the market had a slightly different impact than expected: American films did create a counter-balance to the German production on the distribution market, but they never became very popular. It was the rise of domestic production, in quantity as well as quality, that attracted the bulk of the audiences. The changing 


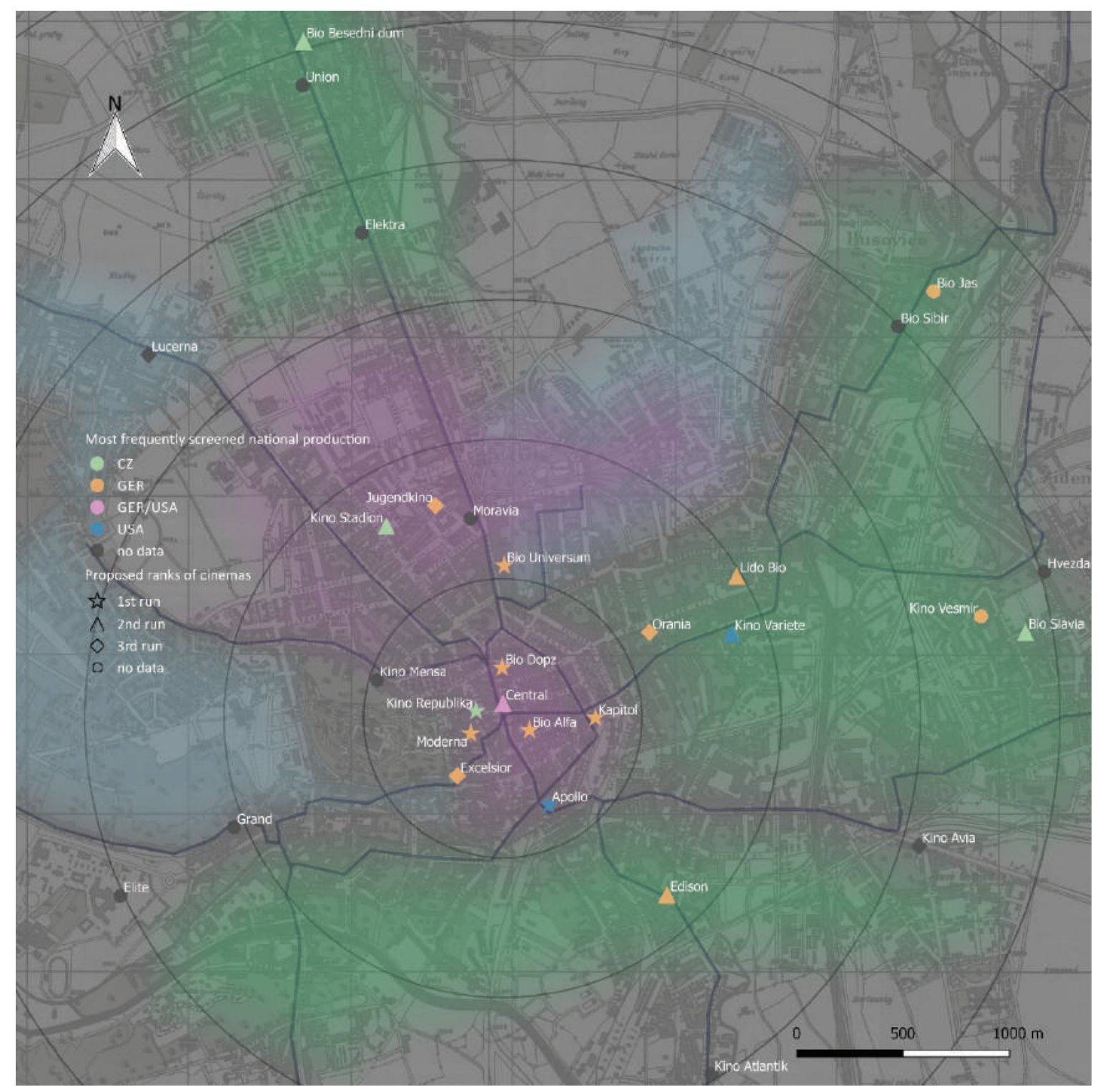

Map 8. Popularity of national productions during the period 1932-1934. Visualisation of the most popular national production in each cinema.

sociopolitical situation in the country appears to be a more significant factor by which audiences reacted by choosing or avoiding films according to their national origin.

Spatial visualisation of the popularity patterns provided an answer to the question of a relationship between the location of cinemas and preferences of their audiences. There seems to be no strict rule that would differentiate the tastes of audiences in relation to their position within the city. Rather than a general pattern, the focus should be directed at single cinemas with specific characterisations, such as, for example, the cinemas Kino Stadion and Kino Republika, where German production never gained the highest popularity, or, in contrast, the cinema Excelsior, where German films managed to retain the loyalty of its audience until the end of the I930s. The map offers a new angle for researching the data, but does not provide the answers. It can help to identify exceptions from the general pattern, but explanations must come from additional archival research. In the case of Kino Republika, it was the initial intention of the owner to establish and operate a cinema focused primarily on domestic production. ${ }^{20}$ 


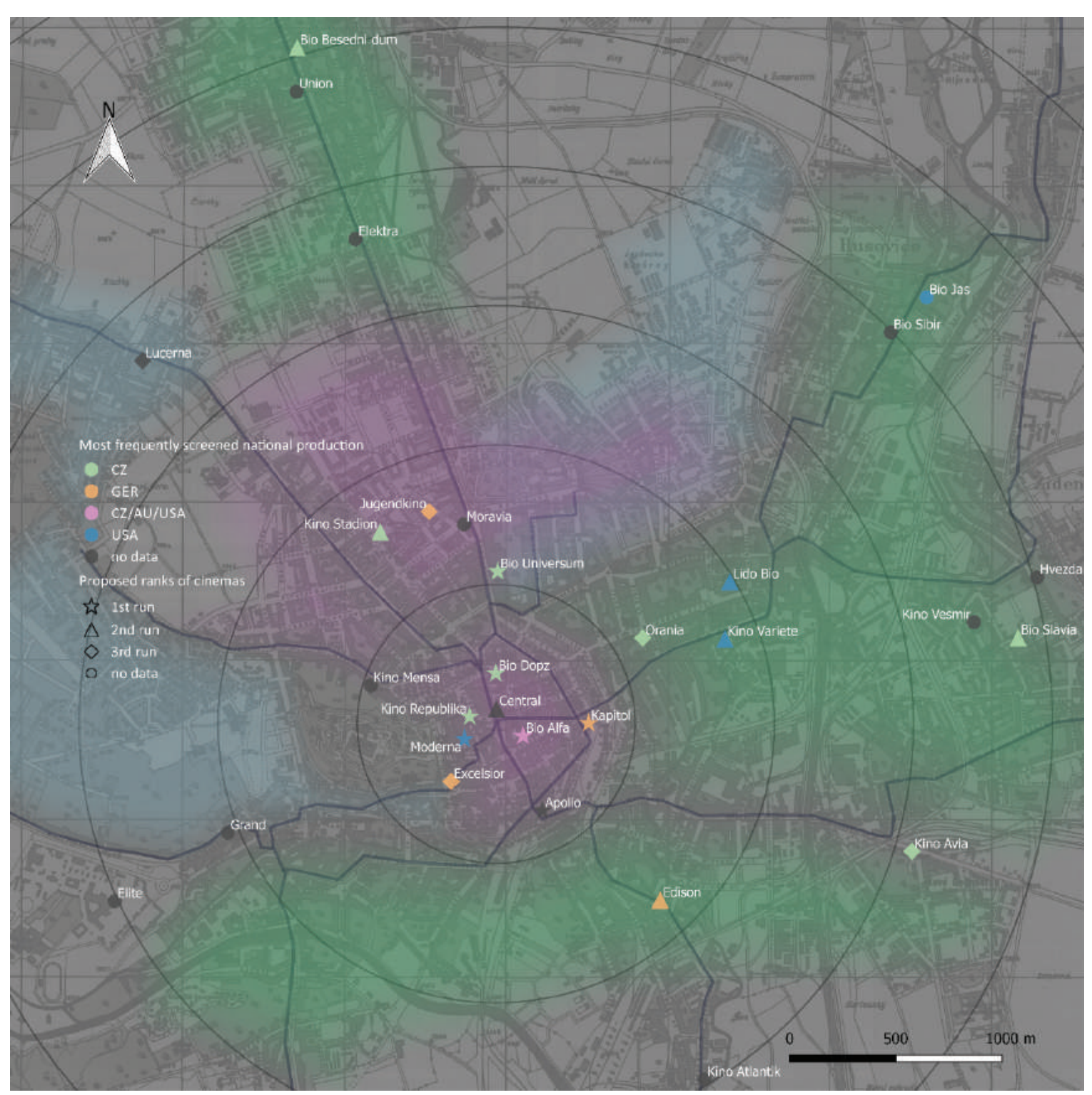

Map 9. Popularity of national productions during the period 1935-1937. Visualisation of the most popular national production in each cinema.

\section{Space, trace and change in time}

According to Laura Horak, 'digital geospatial technologies also have a great potential for tracking the many flows that make up the cinema - the flow of raw materials (chemicals, film stock, ideas), film prints, digital cinema packages, publicity material, and people. ${ }^{2 \mathrm{II}}$ Through an example of tracing the paths of four movies in Brno during the I930s, this study challenges the possibilities of visualisation of the temporal dimension within one map. Each of these films was presented on a cinema programme more than ten times, usually also reappearing in certain cinemas again after some time. Two films, Three from the Gasoline Station (Die Drei von der Tankstelle, 1930) and Love's Command (Liebeskommando, I93I), were produced in Germany and the other two, Madla from the Brickworks (Madla zcihelny, I933) and Mother Kráčmerka (Matka Kráčmerka, I934), in Czechoslovakia.

To follow the trajectory of a film on the map, cinemas were connected by arrows representing the direction in which the film moved from one to another (Maps II-I4). The succession was 


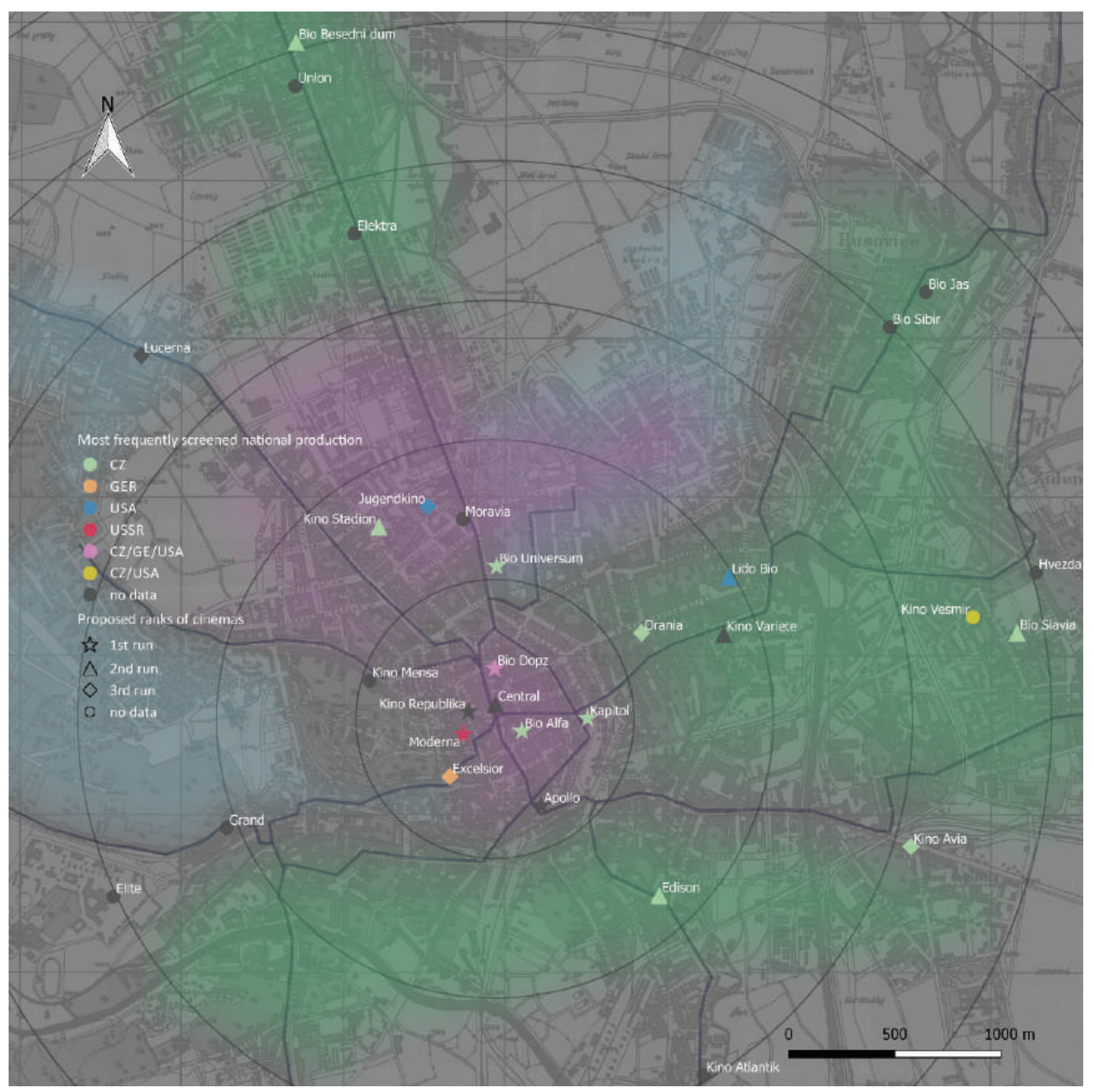

Map 10. Popularity of national productions during the period 1938-1939. Visualisation of the most popular national production in each cinema.

indicated by differentiating the colour of arrows according to the year of screening; however, a detailed pattern of date-to-date flow was not possible to reconstruct. The arrow leaving a cinema bears the colour of the year the film was screened there. However, it was not only a single print of each film that travelled through the city. In some cases, one film had been screened in several cinemas at the same time, which challenges the geospatial visualisation and questions the credibility of displayed trajectory. Unless there is an exact identification of the trajectories of each film print, the visualisation becomes imprecise. In this case study, there are few instances of simultaneous screening of one film. However, to maintain the readability of the maps, the final visualisation of this case study treats each film as a single film print that exceptionally bifurcates in two directions.

While German films enjoyed popularity mainly in the central parts of the city, in cinemas within two kilometres of the central square, and in the cinema Lucerna located in the high-class residential area, Czechoslovak films travelled to more remote parts and districts, mainly to the 


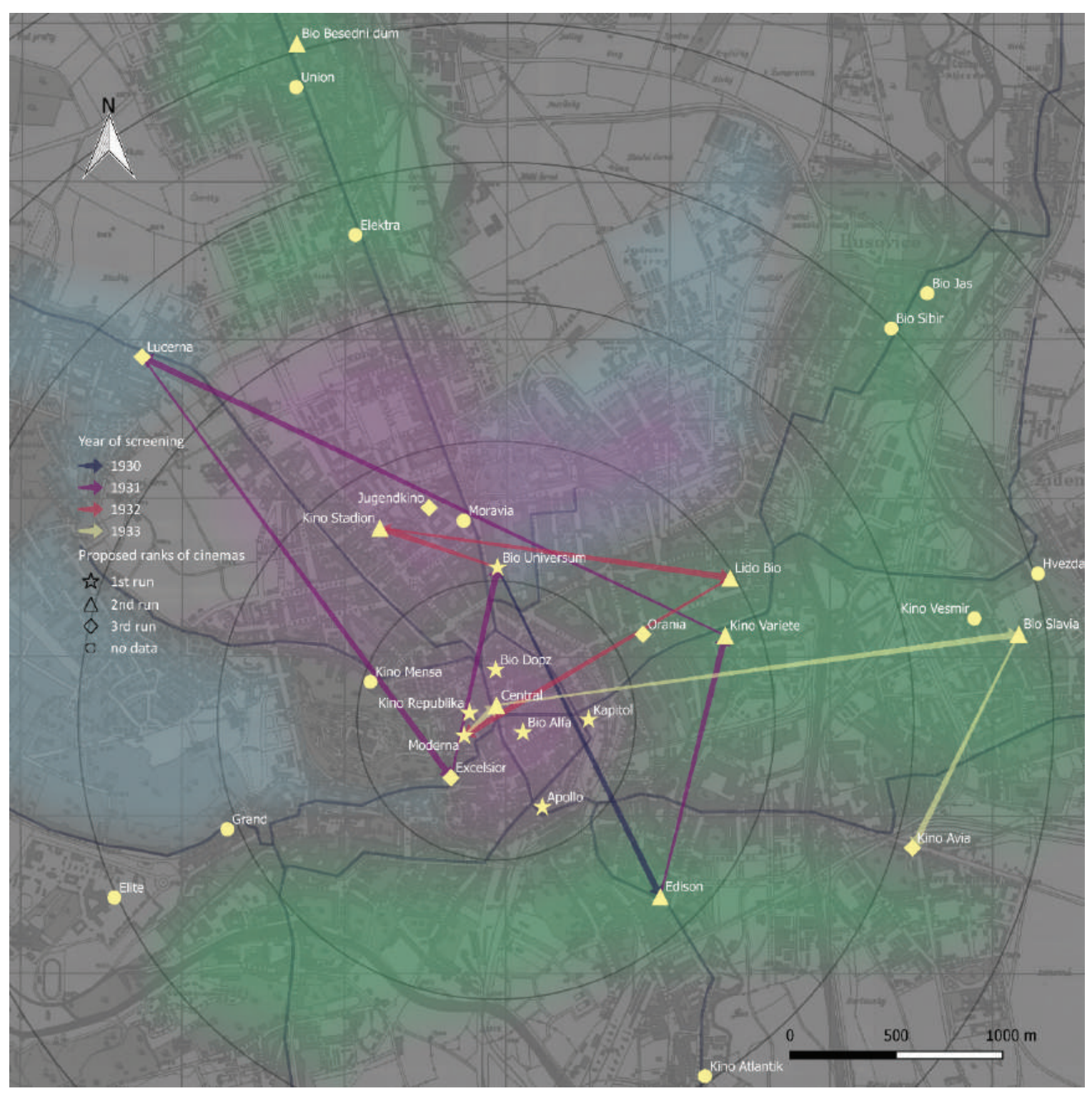

Map 11. Trajectory of the film Three from the Gasoline Station (Die Drei von der Tankstelle, 1930, Germany).

north and east of Brno. This pattern also relates to the national structure of Brno, with the Austro-Hungarian Empire's German-speaking minority having lived there. Germans and Austrians mainly occupied the southern districts of Brno and the wealthy part settled in the city centre. It was not possible to apply the visualisation of the prevailing nationality in the central parts of the city, where the majority of cinemas were located, as the census data were collected for the whole central part as for a single district, consisting of the immediate central area and the neighbouring areas displayed on each of the maps introduced above. Despite this fact, the trajectories of given films loosely reflect the structure of the city, with German films tending to stay within the city centre and Czechoslovak ones leaning towards the northern districts, known as mainly Czechoslovak neighbourhoods.

This methodology made possible an examination of the flows of films within the city. It connects and creates clusters of cinemas based on the similarities in screened films and allows examination of the broader patterns of films' paths in relation to additional spatial 


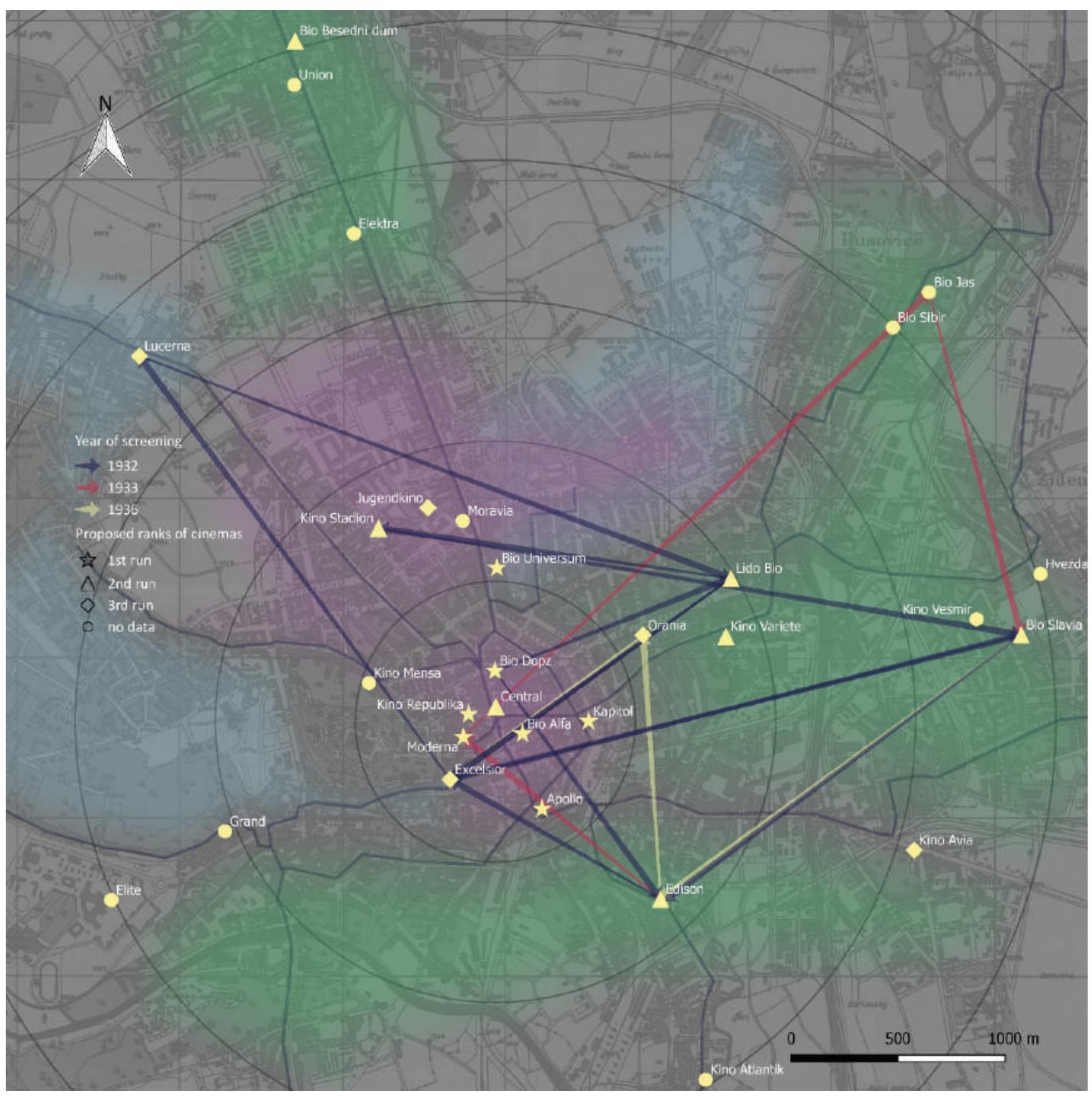

Map 12. Trajectory of the film Love's Command (Liebeskommando, 1931, Germany).

characteristics, as well as detailed comparison of similarities and differences between these patterns. However, it also has several flaws, such as, for example, the lack of precise date-to-date identification of screenings, neglecting the clearance periods - the number of days between two consequent screenings or number of screening days of a film in each cinema. Nevertheless, this method can bring forward relations between spatial objects that are otherwise unseen, and it can also be applied to qualitative historical data, such as, for instance, oral history. Creating mental maps can help to examine the choices and preferences of cinemagoers. There are many ways to visualise the relation of cinemagoers to the cinemas they favoured and to those they avoided or simply did not visit. Did this depend on the distance from their home, the neighbourhood where the venue was located and the element of society which constituted the audience? The spatial visualisation can help to answer these questions and several others: 'How did they get there? How far did they travel? When and why did they decide to come, and where did they encounter the program details or advertising? How will they get home?'22 


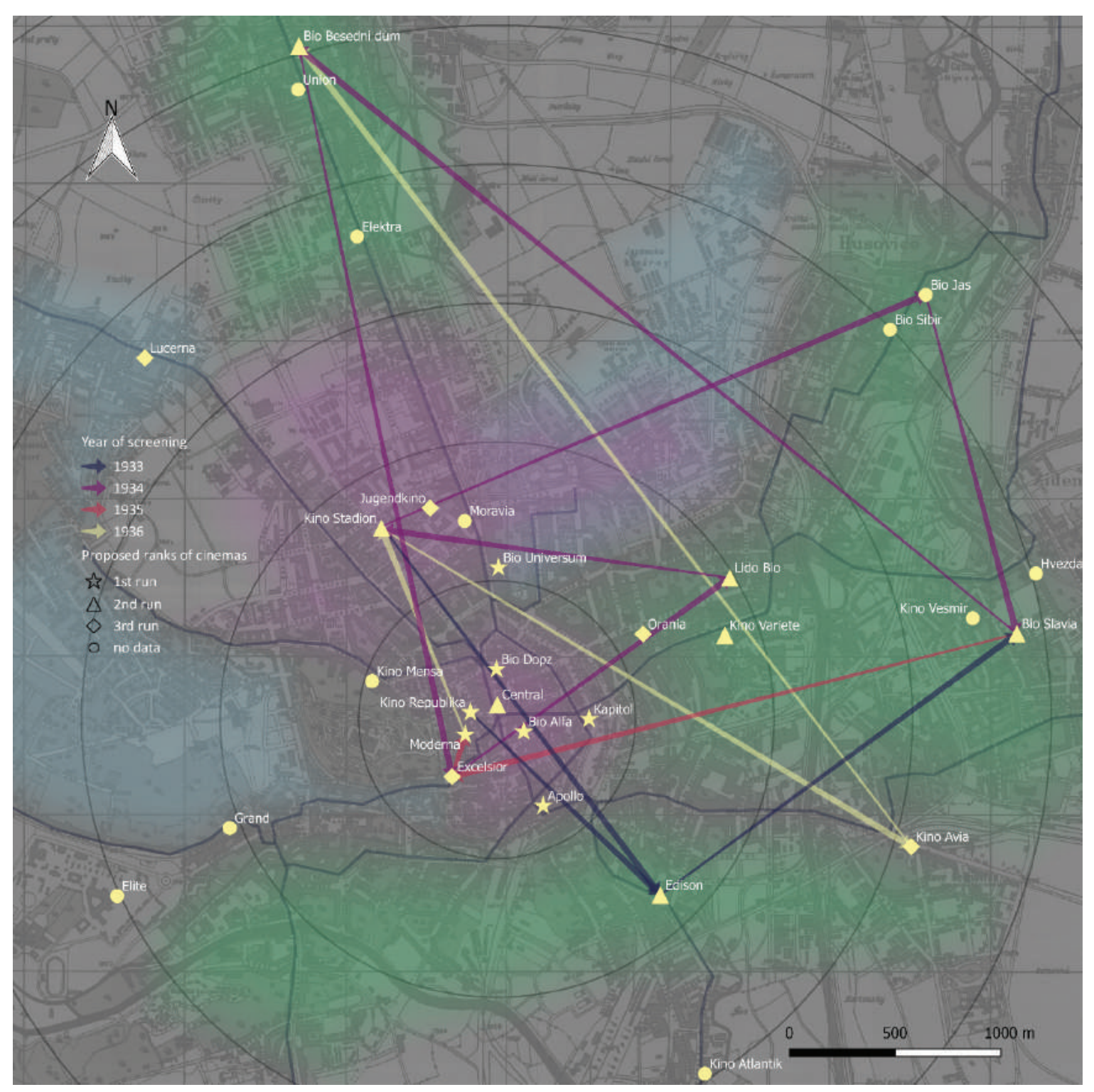

Map 13. Trajectory of the film Madla from the Brickworks (Madla z cihelny, 1933, Czechoslovakia).

\section{Conclusion}

Thematic maps possess the ability to display more than one spatial variable; however, they are limited by the readability of the results. A careful consideration of the layers included in the final visualisation can bring forward relations otherwise suppressed in database spreadsheets or graph displays. Maps can bear information on quantitative as well as qualitative data and combine them in a required form. This article does not offer an exhaustive enumeration of methodologies of spatial analysis; rather, it aims to contribute to the discussion on the possibilities of spatial analysis and the ways to approach historical data from a spatialtemporal perspective.

This article offered several methodologies for handling space and time, both in a single map and in a group of maps. Proximity analysis introduced tight relationships between city, tramways and cinemas. Adding a qualitative characteristic of space, the social structure of the 


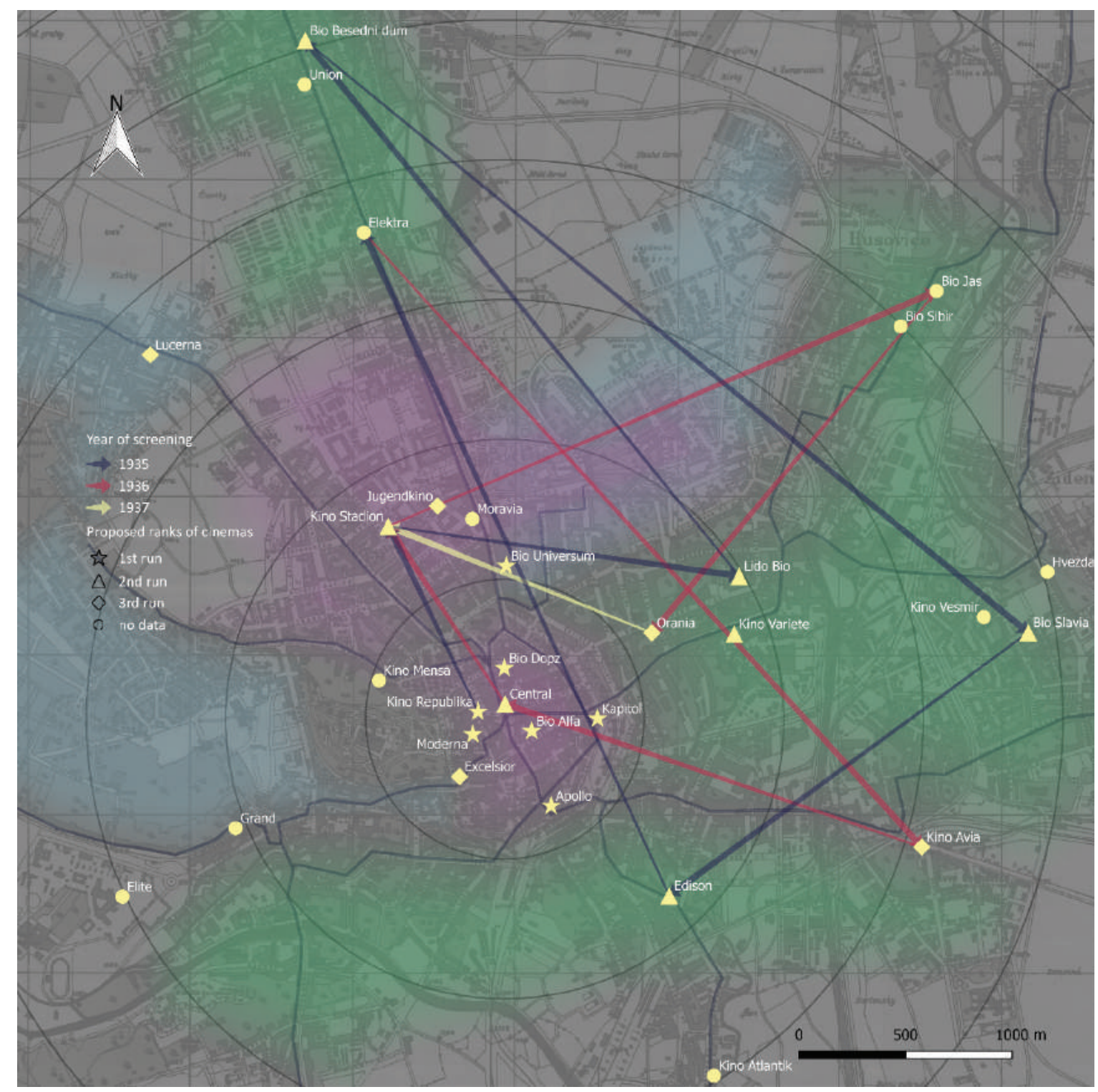

Map 14. Trajectory of the film Mother Kráčmerka (Matka Kráčmerka, 1934, Czechoslovakia).

city, revealed an even more specific pattern of the allocation of cinema venues. The temporal dimension was first included in the example of a change in time, comparing the sizes of cinema venues at the beginning and end of the I930s. The goal of this simple visualisation was to identify a broader phenomenon of growing popularity of cinema culture, while details of the exhibition life of cinemas during the decade were left unexplored. Changing the visualised feature of cinemas from size to ranking created yet another set of clusters, dividing the space between the central part with premiere cinemas and the districts filled with second- and third-run cinemas, as well as partially linking the rankings to the social structure. Additional colours applied to the cinemas according to the most popular national productions did not reveal any specific pattern of similarities or differences between preferences of audiences of premiere cinemas and neighbourhood cinemas; however, it supported the hypothesis that preferences changed across time in relation to the changing sociopolitical mood in the country. The final visualisation tried to challenge the difficulties associated with the display of the temporal dimension by tracking the 
flow of film screenings within the city during the whole decade. This method still struggles with imprecisions and ambiguities; however, it managed to display connections between cinemas based on the same screened films. Through this very limited example, the clusters of cinemas appeared to differ according to the country of origin of the film; while the Czechoslovak films travelled on a broader trajectory around the city, the German films stayed closer to the city centre and to the southern parts of the city. It would be an objective of a further examination of a greater number of film trajectories to argue the hypothesis insinuated in this example. The aim of this study was to accentuate the importance of spatial visualisation and analysis on several examples and to encourage the application of geospatial visualisation methods in future cinema history research.

\section{Notes}

I. D.J. Bodenhamer, "The Potential of Spatial Humanities," in The Spatial Humanities. GIS and the Future of Humanities Scholarship, ed. David J. Bodenhamer, John Corrigan and Trevor M. Harris (Bloomington: Indiana University Press, 2010), I4-30.

2. R. Maltby, "On the Prospect of Writing Cinema History From Below," Tijdschrift voor Mediageschiedenis 9, no. 2 (2006): 74-96.

3. R. Maltby, D. Biltereyst and P. Meers ed., Explorations in New Cinema History: Approaches and Case Studies. (Malden: Wiley-Blackwell, 2oII).

4. Going to the Show, http://gtts.oasis.unc.edu/; Mapping Movies, http://www.mappingmovies.com/; Australian Cinemas Map, http://auscinemas.flinders.edu.au/.

5. S. Caquard, D. Naud and B. Wright, "Mapping Film Audiences in Multicultural Canada: Examples from the Cybercartographic Atlas of Canadian Cinema," in Locating the Moving Image: New Approaches to Film and Place, ed. Julia Hallam and Les Roberts (Bloomington: Indiana University Press, 20I4), I30-49.

6. A. Davidson, C. Arrowsmith and D. Verhoeven, "A Method for the Visual Representation of Historic Multivariate Point Data," Advances in Cartography and GIScience, Volume 2. Lecture Notes in Geoinformation and Cartography 6 (20II): I63-I78.

7. D. Verhoeven and C. Arrowsmith, "Mapping the III-Disciplined? Spatial Analyses and Historical Change in the Postwar Film Industry," in Locating the Moving Image: New Approaches to Film and Place, ed. Julia Hallam and Les Roberts (Bloomington: Indiana University Press, 2014)., I06-29.

8. A. Batistová, L. Česálková, P. Skopal and P. Szczepanik, "Cinematic Brno. Documentation of Movie Exhibition History and Cinema-goers' Preferences in Brno, I918-I945”, https://www.phil.muni.cz/filmovebrno/?id= o\&lang=I, consulted 20 March 2018.

9. Bodenhamer, "The Potential of Spatial Humanities," 27.

Io. Jeffrey Klenotic, "Putting Cinema History on the Map," in Explorations in New Cinema History: Approaches and Case Studies, ed. Richard Maltby, Daniel Biltereyst and Philippe Meers (Malden: John Wiley \& Sons, 20II), 58-84; Doreen Massey, For Space (London and Thousand Oaks: Sage Publications, 2005), I77-I95.

II. Ian Gregory, "Exploiting Time and Space: A Challenge for GIS in the Digital Humanities," in The Spatial Humanities: GIS and the Future of Humanities Scholarship, ed. David J. Bodenhamer, John Corrigan and Trevor M. Harris (Bloomington: Indiana University Press, 2010), 59.

I2. L. Česálková, “Sousedská kina. Socio-kulturní rozměr provozu brněnských sokoloven ve 20. a 30. letech 20. století,” in Filmové Brno. Dějiny lokální filmové kultury, ed. Lucie Česálková and Pavel Skopal (Prague: Národní filmový archiv, 20ı6), I6I-I79.

I3. The price of a cinema ticket in the I930s differed in the central cinemas, where it could cost eight crowns, compared to the district neighbourhoods, where it usually did not exceed two crowns. According to the memories of interviewees, the price of a tram ticket would be around two crowns. See, for example, Lukáš Skupa, "Legrace a dobrodružství - co nejblíž a lacino. Pozice kina ve všedním životě brněnských dětí ve 3o. letech,” in Filmové Brno. Dejiny lokální filmové kultury, ed. Lucie Česálková and Pavel Skopal (Prague: Národní filmový archiv, 20I6), 247-27I. 
I4. Brno Architecture Manual is a project mapping the architecture of Brno dating from I9I8 -I945 https://www. bam.brno.cz/.

I5. Česálková, “Sousedská kina”; Skupa, "Legrace a dobrodružství”.

I6. Terézia Porubčanská, "Filmová kultúra v Brne v tridsiatych rokoch. Porovnávanie diváckych preferencií v priestorovom a spoločenskom kontexte” (master thesis, Masaryk University, 20I7), 3I-34.

I7. Lukáš Skupa, "Dobývání ,zlatých dolů’. Obměna vlastníků kinematografických licencí v Brně I920-I926," Iluminace, 2I (3/75) (2009): 57-70.

I8. Gernot Heiss and Ivan Klimeš ed., Obrazy času: Český a rakouský film 30. let/Bilder der Zeit: Tschechischer und österreichischer Film der zoer Jahre (Prague and Brno: NFA - OSI Brno, 2003), 408-4IO.

I9. The popularity of German films in Prague similarly declined in the second half of the decade as a result of the Nazification of German film production. For more on film popularity in Prague premiere cinemas, see: Szczepanik, "Hollywood in disguise. Practices of exhibition and reception of foreign films in Czechoslovakia in the i930s."

20. Terézia Porubčanská, “Filmová kultúra v Brne,” 6I-62.

2I. Laura Horak, "Using Digital Maps to Investigate Cinema History,” in The Arclight Guidebook to Media History and the Digital Humanities, ed. Charles R. Acland and Eric Hoyt (Sussex: REFRAME Books, 2016), 73.

22. Deb Verhoeven, Kate Bowles and Colin Arrowsmith, "Mapping the Movies," in Digital Tools in Media Studies, ed. Michael Ross, Manfred Grauer and Bernd Freisleben (Bielefeld: Transcript Verlag, 2009), 73.

\section{Biography}

Terézia Porubčanská has master's degrees in Geography from the University of Pavol Jozef Safarik in Kosice, Slovakia and in Film Studies from Masaryk University in Brno, Czech Republic. She is a PhD candidate at the Masaryk University in Brno and the University of Antwerp, preparing her doctoral thesis on the methods of comparative research in new cinema history with a case study of Brno, Antwerp and Ghent. Her PhD is funded by the Vandenbunder Baillet Latour Chair for Film Studies and Visual Culture. 